\title{
O Regime de Proteção à Propriedade Intelectual como Recurso de Poder nas Relações Internacionais
}

The Intellectual Property Regime as Source of Power in International Relations

\author{
Stephanie Gruszka Vendruscolo ${ }^{1}$
}

\begin{abstract}
RESUMO
O objetivo do presente trabalho é analisar a propriedade intelectual e sua influência na distribuição de poder nas relações internacionais. Questiona-se se o discurso legitimador do regime internacional de proteção à propriedade intelectual produz os benefícios a que se propõe e quais foram as consequências de sua implementação. A análise de dados bibliográficos, bem como de estatísticas fornecidas pela $\mathrm{OMPI}^{2}$ nos ajudam a entender as implicações do regime e sua interferência nas relações de poder internacionais.
\end{abstract}

Palavras-chave: Propriedade Intelectual, Recurso de Poder, Relações Internacionais

\begin{abstract}
The objective of this paper is to analyze the intellectual property and its influence on the distribution of power in international relations. The question is if the legitimizing discourse of the intellectual property international regime produces the benefits that are proposed and what were the consequences of its implementation. The analysis of bibliographic data and the statistics provided by WIPO help us to understand the implications of the regime and its interference in the relations of international power.
\end{abstract}

Keywords: Intellectual Property; Source of Power; International Relations

\section{INTRODUÇÃO}

O reconhecimento da tecnologia como fonte de desenvolvimento tem sido crescente nas últimas décadas. 0 número de patentes registradas em um país é um dos principais indicadores do seu desenvolvimento tecnológico. Comumente, utiliza-se a justificativa de que quanto maior a regulamentação jurídica da propriedade intelectual, maior será a proteção à propriedade intelectual e maior será a transferência de tecnologia. Desse

\footnotetext{
${ }^{1}$ Bacharel em Relações Internacionais pela UNICURITIBA e Bacharel em Direito pela Universidade Federal do Paraná. Curitiba, Paraná, Brasil, 2015.

${ }^{2}$ Organização Mundial da Propriedade Intelectual

Conjuntura Global, vol. 5 n. 1, jan./abr., 2016, p. 152-167. 
modo, havendo transferência tecnológica, haverá desenvolvimento em pesquisa e inovação do país que concedeu a patente, e com isso, haverá desenvolvimento econômico ${ }^{3}$.

A nova configuração internacional caracterizada pela tentativa de universalização da proteção à propriedade intelectual congrega os interesses de inúmeros atores. 0 desenvolvimento da capacidade cientifica e tecnológica implica no acréscimo da importância do acesso à produção do conhecimento nos cenários nacionais e internacionais. A crescente relevância dada à propriedade intelectual nos foros de discussão global, evidencia a nova ênfase dada ao assunto. É importante salientar que a propriedade intelectual não se resume apenas à interesses econômicos, mas faz parte de toda uma dinâmica de poder nas relações internacionais.

\section{O novo cenário internacional e a propriedade intelectual}

A globalização possui várias dimensões: ambiental, militar, econômica, social, política, dentre outras. Não é um fenômeno recente, mas conforme NYE JR.4 "a sua modalidade contemporânea é mais rápida e intensa", e tem sido acompanhada de uma incerteza constante. Com a globalização, há a tendência dos Estados buscarem a cooperação intergovernamental para resolver problemas de natureza transnacional, como é o caso da legislação sobre a propriedade intelectual ${ }^{5}$.

A propriedade intelectual é o conjunto de duas coisas: a atividade privada (ideias, invenções e demais expressões criativas) e o desejo público de classificar essas invenções como propriedade. Abarca os bens intelectuais, mas não todos eles, sendo estabelecidos parâmetros de protegibilidade que geralmente traçam a utilidade comercial ou expressão artística ${ }^{6}$.

\footnotetext{
${ }^{3}$ GUISE, Mônica Steffen. Propriedade Intelectual no Mundo Contemporâneo: Fomento ao desenvolvimento? Pág. 4. Disponível em: <http://www.egov.ufsc.br/portal/conteudo/propriedade-intelectual-no-mundocontempor\%C3\%A2neo-fomento-ao-desenvolvimento>. Acessado em: 02 de novembro de 2015.

${ }^{4} \mathrm{NYE}$ Jr, Joseph S. Cooperação e conflito nas relações internacionais. Uma leitura essencial para entender as questões da política mundial. Tradução: Henrique Amat Rêgo Monteiro. Pág. 247. São Paulo: Editora Gente,2009.

${ }^{5}$ SARFATI, Gilberto. O poder estrutural e o poder brando das empresas Multinacionais. In: Revista de Economia \& Relações Internacionais. volume 7/ número 13/ julho de 2008.

${ }^{6}$ SHERWOOD, Robert M. Propriedade Intelectual e Desenvolvimento Econômico. São Paulo: Edusp, 1992.

Conjuntura Global, vol. 5 n. 1, jan./abr., 2016, p. 152-167. 
Na nova dinâmica internacional de poder o controle da tecnologia de ponta passou a ser o componente estratégico fundamental. GANDELMAN7 enfatiza que aquele que detém a posse do conhecimento, possui poder estrutural, e na relação entre autoridade e mercado, possui a capacidade de mudar o âmbito das escolhas oferecidas, podendo adquirir ou negar o acesso ao conhecimento, ou até mesmo ter o controle sobre os meios pelos quais o conhecimento é comunicado. Quanto mais tempo a difusão da nova tecnologia demorar tanto maior será a vantagem comparativa de seu possuidor, seja ele uma empresa ou um Estado. Isto posto, podemos afirmar que a propriedade do conhecimento caracteriza-se como recurso de poder.

\section{As relações de poder no cenário internacional}

Faz-se mister rememorar a clássica divisão do poder em hard power e soft power no âmbito das relações internacionais. 0 primeiro, traduzido como poder duro, caracteriza-se pelas intervenções militares e o uso de recursos econômicos para coagir ou induzir os demais atores internacionais a agirem de modo que se obtenha o resultado pretendido. Seria, portanto, a capacidade de converter recursos em estratégias de modulação de comportamentos. Já o soft power, ou poder brando, atua sobre as percepções do sujeito, incluindo muitas vezes fatores intangíveis como instituições, ideias, valores, cultura e a legitimidade compreendida, de forma que o sujeito seria influenciado de forma amigável a agir conforme os interesses do detentor do poder brando.

NYE JR ${ }^{8}$ define o poder como recursos e como resultados comportamentais. Como recursos, o poder consistiria na utilização de recursos para formular estratégias de conversão e alcançar os resultados pretendidos, como é o caso do poder brando. Como resultados comportamentais é através da capacidade de afetar os outros em relação a algum ponto para alcançar os resultados preferidos, como por exemplo as sanções comerciais.

\footnotetext{
7 GANDELMAN, Marisa. Poder e conhecimento na economia global. 0 regime internacional da propriedade intelectual da sua formação à regras de comércio atuais. Rio de Janeiro: Civilização Brasileira, 2004, pág. 278-283.

8 NYE JR. Joseph S. O futuro do poder. Tradução: Magda Lopes. Pg. 31. Benvirá, 2012.

Conjuntura Global, vol. 5 n. 1, jan./abr., 2016, p. 152-167. 
0 poder brando está associado à fatores intangíveis como instituições, ideias, valores, cultura e a legitimidade percebida das políticas. Assim, quando um agente consegue convencer os demais a adotar o seu ponto de vista, sem o uso da força, sanções econômicas, ou outros meios de coerção, ele está se valendo de seu soft power, ou poder brando. Há ainda a classificação do poder em smart power, ou poder inteligente. Este seria uma terceira via entre o hard power e o soft power, de modo a combinar os dois, e entender o contexto de decisão para alcançar os melhores resultados possíveis. Compreender a evolução cultural e necessidades dos potenciais seguidores é de suma importância para que um agente alcance os seus objetivos.

Com a Revolução Técnico-Científica a ciência foi incorporada definitivamente ao processo produtivo. Consequentemente, a produção e detenção do conhecimento científico passaram a ser forma de diferenciação entre os países, classificando-os em grupos de detentores e não-detentores deste recurso de poder ${ }^{9}$. 0 avanço tecnológico, passa a ser encarado como recurso de poder brando, uma vez que há o interesse em sua difusão controlada, de modo a não contemplar áreas sensíveis e estratégicas, para assim, modular a dinâmica relacional de acordo com interesses do ator detentor de tecnologia. $\mathrm{O}$ alto grau de interdependência e a competividade mundial, ressaltam ainda mais a importância da ciência e do aspecto tecnológico nas relações internacionais. Além disso, a manutenção da capacidade competitiva de um agente depende, fundamentalmente, do desenvolvimento tecnológico e das inovações.

Susan Strange ${ }^{10}$ afirma que as relações internacionais são caracterizadas pelas relações entre poder e interesses, de modo que estes moldam o comportamento dos Estados no Sistema Internacional. Segundo a autora, a estrutura da economia política seria influenciada pelo poder estrutural e pelo poder relacional. Este seria a capacidade de um ator modular o comportamento dos outros atores internacionais, conforme os seus próprios interesses. Já o poder estrutural refere-se à capacidade de delinear as estruturas

\footnotetext{
${ }^{9}$ CARPES, Mariana Montez. O Lugar da Ciência e da Tecnologia nas Relações Internacionais Contemporâneas: antigas e novas relações de poder. Disponível em:< http://www.maxwell.vrac.puc-rio.br/9614/9614_3.PDF>. Pág. 23. Acessado em: 17 de outubro de 2015.

${ }^{10}$ STRANGE, Susan. STRANGE, Susan. "Cave! Hic Dragones: A Critique of Regime Analysis". In KRASNER, Stephen (ed.). International Regimes. Ithaca, New York: Cornell University Press, 1983. 
da política econômica global, ditando a agenda internacional em conformidade com seus interesses.

O poder estrutural seria composto de quatro faces, ou estruturas correlacionadas: segurança, financeira, de produção e de conhecimento. STRANGE11 afirma que não há necessariamente hierarquia entre tais estruturas, e que é comum aos quatro tipos de poder a capacidade que seu possuidor tem de determinar as opções e comportamentos dos outros players. A tecnologia seria a expressão de uma das quatro estruturas de poder da economia política contemporânea, estando inserida na estrutura do conhecimento. Tal estrutura pode ser definida pela capacidade de negar ou controlar acesso à essa fonte de poder $^{12}$, sendo constituída pelo conjunto de normas, crenças e valores de uma sociedade. KEOHANE E NYE13 analisam a tendência de modificação das fontes de poder nas relações internacionais:

A revolução da informação também está afetando o poder medido em termos de recursos, em vez de comportamento. No século XVIII o balanço europeu de poder, território, população e agricultura, forneceu a base para a infantaria, e a França foi a principal beneficiária. No século XIX, a capacidade industrial proveu os recursos que possibilitaram a Grã-Bretanha e, mais tarde, a Alemanha ganhar uma posição dominante. Em meados do século XX, a ciência e particularmente a física nuclear contribuíram crucialmente para os recursos dos Estados Unidos e União Soviética. No próximo século, é provável que a tecnologia da informação, em sentido lato, seja a fonte de poder mais importante. (KEOHANE; NYE JR. 1998 ${ }^{14}$ ).

Em um contexto de interdependência complexa ${ }^{15}$ existem múltiplos canais conectando as sociedades, influenciando o processo de decisão, e restringindo a

\footnotetext{
${ }^{11}$ STRANGE, Susan. States and Markets. London and New York: Pinter, 1988.

${ }^{12}$ CARPES, Mariana Montez. op cit., págs. 43-44.

${ }^{13}$ KEOHANE, Robert O.; NYE JR, Joseph S. Power and Interdependence in the Information Age. In: ESSAY, September/October 1998.

${ }^{14}$ Tradução livre para: The information revolution is also affecting power measured in terms of resources rather than behavior. In the eighteenth-century European balance of power, territory, population, and agriculture provided the basis for infantry, and France was a principal beneficiary. In the nineteenth-century, industrial capacity provided the resources that enabled the Britain and, later, Germany to gain dominance. By the midtwentieth century, science and particularly nuclear physics contributed crucial power resources to the United States and the Soviet Union. In the next century, information technology, broadly defined, is likely to be the most important power resource. KEOHANE, Robert O.; NYE JR, Joseph S. Power and Interdependence in the Information Age. In: ESSAY, September/October 1998.

${ }^{15}$ Conceito inicialmente formulado por Keohane e Nye pelo qual, entende-se que apesar de a interdependência implicar em situações de dependência mútua, não há equilíbrio entre as partes. As inúmeras variáveis existentes nos contextos nacionais e internacionais implicariam em um constante estado de desequilíbrio, onde o processo de barganha passa a ter relevância. KEOHANE, Robert O.; NYE JR, Joseph S. Power and interdependence. 3. ed. New York: Longman, 2001.

Conjuntura Global, vol. 5 n. 1, jan./abr., 2016, p. 152-167. 
autonomia dos atores internacionais, na medida em que o resultado das negociações é fruto do processo de barganha entre tais atores. A grande questão que se coloca é quem detém o conhecimento na atualidade? E como o monopólio da informação é legitimado? SUSAN STRANGE ${ }^{16}$ afirma que na estrutura do conhecimento a autoridade deriva em grande medida da ciência, e o poder continua nas mãos dos grandes empreendimentos, das grandes companhias, que na realidade atuam como operadoras do sistema, sendo os Estados, os reguladores e árbitros do regime.

As multinacionais fazem com que seu interesse prevaleça pela via indireta, ou seja, influenciando a decisão dos Estados. Tal influência ocorre através da modificação de interesses e modulação das preferências estatais, de modo que os interesses das empresas multinacionais possam ser levados em conta pelos Estados, e se possível, sejam coincidentes com os interesses destes. 0 monopólio da informação cientifica, tecnológica e comercial pode importar no controle sobre os fluxos econômicos internacionais, afetando a capacidade de desenvolvimento dos Estados, e sendo meio de manutenção de um status quo de desigualdade na divisão do patrimônio informacional do mundo ${ }^{17}$.

A ampliação conceito de propriedade na normativa internacional contemporânea sobre a propriedade intelectual faz com que um número cada vez maior de bens e serviços seja considerado propriedade privada. As situações nas quais um indivíduo tem o seu acesso a bens e serviços limitados pelo direito de propriedade também aumenta. Tal cenário garante a manutenção da ordem liberal que privilegia a eficiência, não se preocupando com os problemas de distribuição ${ }^{18}$. Por detrás desse quadro estariam os interesses de atores, como é o caso das grandes empresas produtoras de tecnologia, em maximizar seus crescentes lucros, controlando quem tem acesso ao conhecimento e quem não o tem.

A interdependência e a globalização econômica favoreceram a aceleração nos fluxos de comércio e investimento. Com a revolução tecnológica restou-se comprovado que as transações comerciais não são apenas de bens e serviços, mas também de

\footnotetext{
${ }^{16}$ STRANGE, Susan. Op cit.

17 BARBOSA, Denis Borges. Trips e a Experiência Brasileira. In: VARELLA, Marcelo Dias (org.) Propriedade Intelectual e Desenvolvimento. Pág. 136. São Paulo: Lex Editora, 2005.

18 GANDELMAN, Marisa. Op cit., págs. 216-217.

Conjuntura Global, vol. 5 n. 1, jan./abr., 2016, p. 152-167. 
conhecimentos e ideias ${ }^{19}$. 0 crescimento da relevância dos produtos de alta tecnologia na balança comercial dos países, fez com que a propriedade intelectual e suas variáveis passassem a ser pauta constante na agenda internacional.

\section{A falibilidade do argumento de que o recrudescimento da proteção à Propriedade Intelectual invariavelmente conduz ao desenvolvimento}

Os países detentores de conhecimento afirmam que o recrudescimento do sistema de proteção à Propriedade Intelectual se justifica na medida em que promove a inovação e que esta seria condição fundamental para a promoção do desenvolvimento econômico e social ${ }^{20}$. 0 principal argumento para o estabelecimento de altos padrões internacionais de proteção à propriedade intelectual, seria o impacto positivo sobre a criatividade e inovação em escala global.

Há uma constante pressão para que os países em desenvolvimento adotem as políticas previstas nas políticas de desenvolvimento internacional. Num quadro histórico recente, o Consenso de Washington ${ }^{21}$ prescreveu uma série de boas políticas e boas instituições para os países atrasados economicamente, especificamente para os da América Latina. Políticas como a liberalização dos investimentos e comércio internacional, a privatização e a desregulamentação foram pontos frisados. Foram elencadas uma série de instituições determinantes do sucesso econômico de um país,

\footnotetext{
${ }^{19}$ CHRISTOVÃO, Daniela. A proteção da propriedade intelectual: uma abordagem internacional. pag.222-223 In: MELO, José Marques de; et al. (org). Sociedade de conhecimento: aportes latino-americanos. São Bernardo do Campo: UMESP: Cátedra Unesco para o Desenvolvimento Regional, 2005.

${ }^{20}$ DUPAS, Gilberto. Propriedade Intelectual: tensões entre a lógica do capital e os interesses sociais. In: VILLARES, Fábio (org.) Propriedade Intelectual: tensões entre o capital e a sociedade. Pág. 25 . São Paulo: Paz e Terra, 2007.

${ }^{21}$ Realizado em novembro de 1989, em Washington D.C, cujo objetivo primário era o de promover uma reunião para avaliar as reformas econômicas implementadas na América Latina. Elaborou uma série de prescrições relativas à condução macroeconômica nos países latino-americanos, criando as dez regras de ajuste econômico, de caráter neoliberal. No entanto, cabe frisar que o Consenso de Washington não apresentou políticas novas, mas sim, registrou com aprovação, o grau de efetivação de políticas já recomendadas em diferentes momentos por diferentes agências. BATISTA, Paulo Nogueira. O Consenso de Washington. A visão neoliberal dos problemas latino-americanos. $1994 . \quad$ Disponível em: <http://www.usp.br/fau/cursos/graduacao/arq urbanismo/disciplinas/aup0270/4dossie/nogueira94/nog94cons-washn.pdf>. Acessado em: 22 de outubro de 2015. 
como é o caso da democracia, o judiciário independente, o robustecimento da proteção à propriedade privada, dentre outros 22 .

Com o Consenso de Washington, divulgou-se a ideia de que os países desenvolvidos obtiveram o sucesso econômico graças a políticas como a Lei de Patentes e os demais direitos de propriedade intelectual. A proteção dos direitos sobre os bens do conhecimento teria sido instrumento poderoso de desenvolvimento econômico na medida em que incentivaria à inovação, gerando novas tecnologias e promovendo a prosperidade nacional. Os países em desenvolvimento também receberiam os benefícios, na medida em que haveriam maiores fluxos de tecnologia e investimentos direcionados à periferia tecnológica.

Ao analisarmos os dados fornecidos pela Organização Mundial da Propriedade Intelectual constatamos a tendência crescente dos pedidos de patentes ao longo de quase 20 anos. Neste período, houve um aumento de cerca de 150\% nas aplicações de patentes ao redor do mundo.

\section{Gráfico 1:}

\section{Patent applications and grants worldwide}

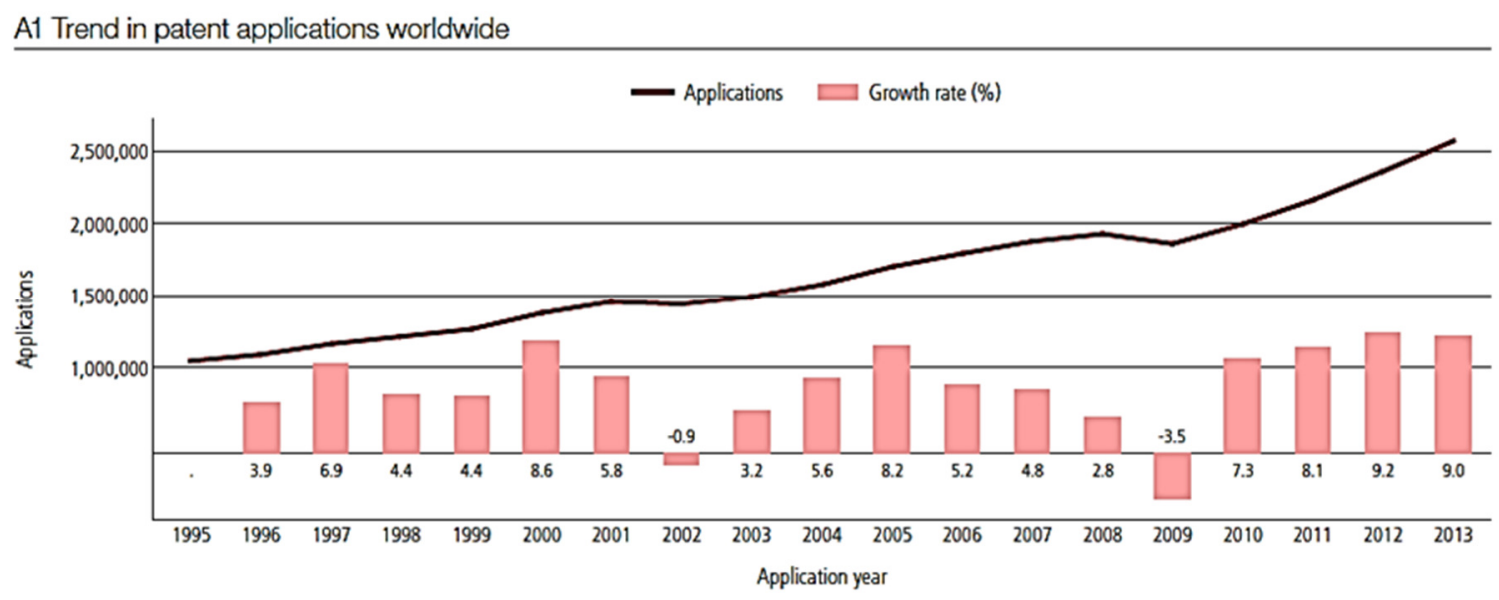

Note: WIPO estimates cover 139 patent offices and include direct applications and Patent Cooperation Treaty national phase entry data.

Source: WIPO statistics database, October 2014.

Fonte: Banco de dados estatísticos da Organização Mundial da Propriedade Intelectual ${ }^{23}$

\footnotetext{
${ }^{22}$ CHANG, Ha-Joon. Chutando a escada. A estratégia do desenvolvimento em perspectiva histórica. Tradução: Luiz Antônio Oliveira de Araújo. págs. 12-13 São Paulo: Editora UNESP, 2004.

23 WORLD INTELLECTUAL PROPERTY ORGANIZATION. World Intellectual Property Indicators. In: Economics \& Statistics Series. Pag.22, 2014.

Conjuntura Global, vol. 5 n. 1, jan./abr., 2016, p. 152-167. 
Cabe apontar que o período abrangido pelo gráfico acima anexado é o imediatamente posterior à celebração do Acordo TRIPS24. 0 aumento crescente das aplicações de patente ao redor do mundo, demonstra que o Acordo TRIPS ampliou significativamente a proteção aos direitos de propriedade intelectual, concedendo patentes para produtos e processos em todos os campos tecnológicos.

A matéria de Propriedade Intelectual tem sido discutida internacionalmente sob duas perspectivas. A primeira é favorável à ampliação e harmonização internacional dos direitos de propriedade intelectual, alegando que a concessão de direitos exclusivos aumenta a possibilidade de apropriação do conhecimento, podendo estimular o investimento em inovação. Assim, os foros multilaterais de proteção à tais direitos deveriam se preocupar com aspectos exclusivamente técnicos, não sendo influenciados por preocupações sociais, por exemplo.

Por outro lado, há a visão desenvolvimentista da Propriedade Intelectual, entendendo-a como instrumento de capacitação. Os que se filiam à tal perspectiva entendem que qualquer tentativa de ampliação dos direitos de propriedade industrial deve ser precedida de avaliação criteriosa, de forma a sopesar de forma equilibrada os direitos e obrigações ao interesse público. Afirmam que os tais direitos se inserem no rol de instrumentos da política industrial e tecnológica de cada país ${ }^{25}$.

O gráfico 1 demonstrou que nas duas últimas décadas houve um aumento vertiginoso da concessão de patentes. No entanto, tal aumento tem sido muito criticado. Isso porque, argumenta-se que houve o incremento no número de patentes de baixa qualidade, cuja novidade ou inventividade são discutíveis, como é o caso do patenteamento das propriedades medicinais da Cúrcuma ${ }^{26}$. A concessão exagerada das

24 O TRIPS foi negociado no final da Rodada Uruguai no Acordo Geral de Tarifas e Troca (GATT) em 1994. LAMPREIA, Luiz Felipe Palmeira. Resultados da Rodada do Uruguai: uma tentativa de síntese. In: Estud. av. vol.9 no.23 São Paulo Jan./Apr. 1995. Disponível em: <http://www.scielo.br/scielo.php?pid=S0103$40141995000100016 \&$ script=sci arttext>. Acessado em: 15 de novembro de 2015.

25 JAGUARIBE, Roberto; BRANDELLI, Otávio. Propriedade Intelectual: espaços para os países em desenvolvimento. In: VILLARES, Fábio (org.) Propriedade Intelectual: tensões entre o capital e a sociedade. pag. 286 São Paulo: Paz e Terra, 2007

26 Aqui, podemos citar o exemplo do patenteamento da Cúrcuma (turmeric) por dois doutores sul-asiáticos. A patente sobre as propriedades medicinais da raiz de cúrcuma foi concedida mesmo sendo conhecidas por centenas, ou até mesmo milhares de anos na Índia. Apesar de as propriedades medicinais da raiz serem amplamente conhecidas pela cultura tradicional indiana, elas não haviam sido "publicadas". STIGLITZ, Joseph E. Economic Foundations of Intellectual Property Rights. In: Duke Law Journal, pag. 1693- 1724. 2008. 
patentes tem afetado negativa e indevidamente o domínio público, retardando o desenvolvimento cientifico e tecnológico dos países. Muitas dessas patentes não geram pesquisa, ou qualquer avanço no conhecimento, mas impõem custos sociais sem qualquer benefício correspondente.

Países como Estados Unidos, Japão e Alemanha, que defendem o fortalecimento da proteção à propriedade intelectual, afirmam haver uma relação de causalidade entre tal proteção e a atração de investimentos. Todavia, o que tem se verificado é que o aumento da proteção aos direitos de propriedade intelectual, intensificado com o Acordo TRIPS, acabou por gerar a concentração da atividade inovadora em poucos países desenvolvidos e a desnacionalizando a produção de países em desenvolvimento. Os gráficos abaixo corroboram tal entendimento:

\section{Gráficos 2 e 3:}
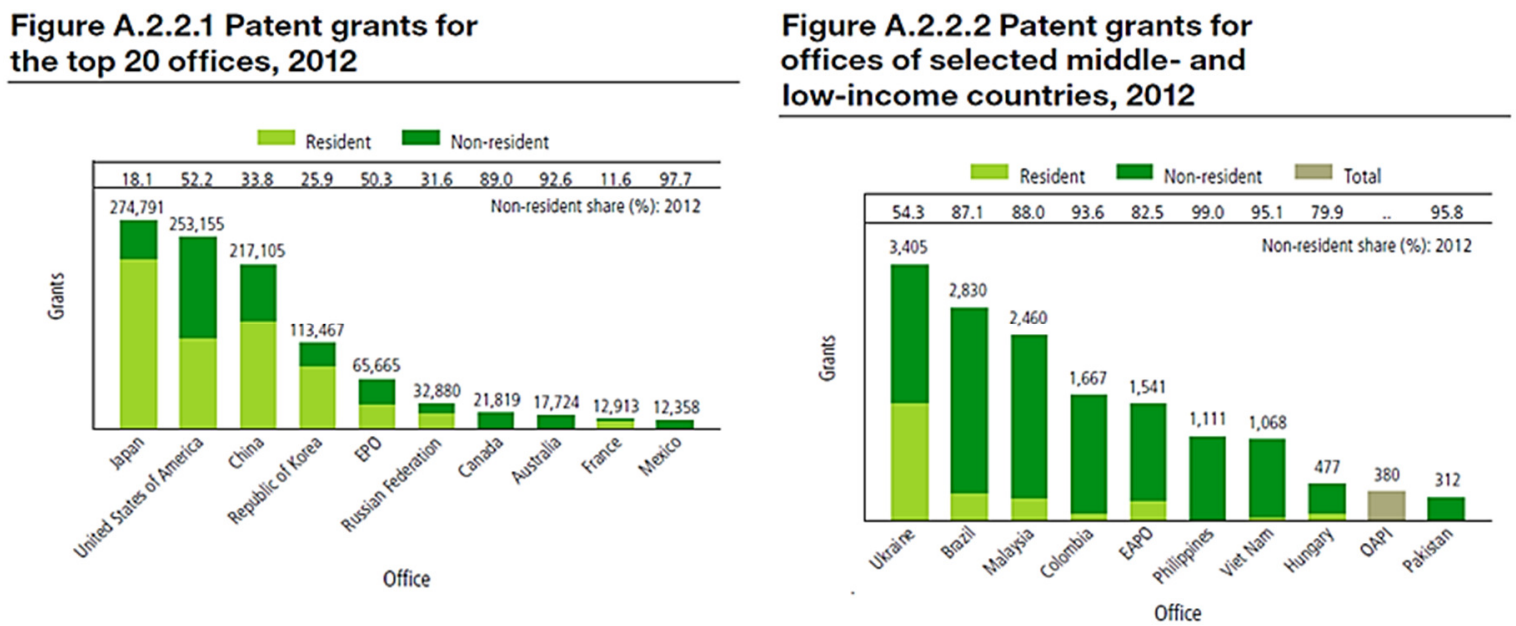

Fonte: Banco de dados estatísticos da Organização Mundial da Propriedade Intelectual27

A análise dos gráficos 2 e 3 evidencia que apesar de ter havido o aumento do número de patentes registradas ao redor do mundo (gráfico 1), a produção patentária não se deu de forma proporcional entre as nações. Isso porque em países em desenvolvimento como Ucrânia, Brasil, México, Colômbia, e outros, a grande maioria das concessões de

\footnotetext{
${ }^{27}$ WORLD INTELLECTUAL PROPERTY ORGANIZATION. World Intellectual Property Indicators. In: Economics \& Statistics Series. Pag.53, 2013. 
patentes são para não-residentes. As patentes concedem o monopólio industrial e tecnológico sobre um bem durante os 20 anos seguintes à sua concessão, depreendendose, a partir daí, que a relevância econômica e industrial de um país durante duas décadas está intimamente relacionada com o número de patentes concedidas no presente.

STIGLITZ ${ }^{28}$ afirma que o que separa países desenvolvidos dos em desenvolvimento não é apenas a disparidade ou a lacuna quanto à quantidade de recursos que cada um dispõe. A disparidade de conhecimento é uma determinante forte para tal diferenciação. 0 autor também argumenta que o sistema de proteção à propriedade intelectual tal qual o conhecemos acaba por criar uma proteção excessivamente forte à tais direitos, e acaba por impedir a inovação. Tal afirmação vai diretamente contra às premissas daqueles que defendem o fortalecimento da proteção à propriedade intelectual como forma de estimular a atividade inovativa. Para VARELLA ${ }^{29}$ no plano global há três grandes categorias de países: aqueles que produzem tecnologia e dela obtém patentes; aqueles que podem pagar royalties para adaptar essa tecnologia à sua produção doméstica e, por fim, o grupo excluído da produção e reprodução tecnológica.

Os países bem-sucedidos em matéria de inovação e desenvolvimento tecnológico contaram com uma intensa e persistente participação do Estado. QUIJANO ${ }^{30}$ afirma que a inovação não é uma atividade neutra, pelo contrário, ela serve à objetivos que as empresas e nações perseguem, em maior ou menor medida. 0 sucesso na atividade inovativa está intrinsicamente relacionado à capacidade de adaptação dos sistemas nacionais de inovação aos objetivos das políticas industriais, de modo a promover a aprendizagem tecnológica de maneira eficiente.

A institucionalização do regime internacional de propriedade intelectual fundamenta-se no conceito de propriedade privada e nos propósitos aos quais ela deve servir. Os países desenvolvidos, buscavam promover uma ordem liberal, onde o Estado deveria ater-se à garantir os direitos de propriedade, o livre contrato e a garantia de que os compromissos assumidos seriam cumpridos, já que com os regimes, as políticas nacionais passariam a atuar de forma coordenada31. Quanto à transferência tecnológica,

\footnotetext{
${ }^{28}$ STIGLITZ. Joseph. Op, cit. Pag. 1694.

${ }^{29}$ VARELLA, Marcelo Dias. Políticas Públicas para Propriedade Intelectual no Brasil. In: VARELLA, Marcelo Dias. (org.) Propriedade Intelectual e Desenvolvimento. Pág. 176. São Paulo: Lex Editora, 2005.

${ }^{30}$ QUIJANO, José Manuel. op cit., pag. 182-183.

${ }^{31}$ GANDELMAN, Marisa. op cit., pág. 158-159.

Conjuntura Global, vol. 5 n. 1, jan./abr., 2016, p. 152-167. 
CHANG32 afirma que "um país quando se adianta aos outros, sente-se naturalmente estimulado a se valer de seu poder político e econômico para se adiantar ainda mais". Assim, as nações desenvolvidas tecnologicamente, passaram a adotar medidas para impedir a transferência tecnológica às menos desenvolvidas.

Os países desenvolvidos tecnologicamente mudaram de postura de acordo com a posição relativa que ocupavam no ranking de desenvolvimento tecnológico internacional. Países que quando se encontravam em situação de desenvolvimento valeram-se amplamente da proteção à indústria nascente, cooptação de mão-de-obra especializada, contrabando de máquinas, espionagem industrial e violação de marcas e patentes. Cabe frisar que apesar do regime internacional de proteção à propriedade intelectual ter sido instaurado no final do século XIX, ao longo do século XX os países mais desenvolvidos seguiram violando-o rotineiramente ${ }^{33}$.

A ideia de que quanto maior a proteção aos direitos de propriedade intelectual maior será o desenvolvimento econômico é vaga. Isso porque, ignora-se o grau de diversidade entre os países, e o fato de que não há um modelo único para o desenvolvimento, já que há uma mescla de princípios orientadores, atores que influenciam e objetivos que cada país busca. 0 relevante não é a mera proteção aos direitos de propriedade, mas sim, qual direito está sendo protegido e em que condições ${ }^{34}$.

Há uma incoerência entre o apregoado pelas nações desenvolvidas para a promoção do desenvolvimento e as estratégias realmente adotadas por elas para seu catch-up tecnológico. Os países que atingiram a fronteira tecnológica, em sua ampla maioria, se beneficiaram de uma forma ou de outra, de condições de apropriação mais brandas no cenário internacional ${ }^{35}$.

\section{Considerações Finais}

\footnotetext{
32 GANDELMAN, Marisa. op cit., pág. 94.

33 CHANG, Ha-Joon. Op. Cit., pag. 104

${ }^{34}$ CHANG, Ha-Joon. Op. cit., pag 145.

${ }^{35}$ ALBUQUERQUE, Eduardo da Motta e. Propriedade Intelectual e estratégias para o desenvolvimento. In: VILLARES, Fábio (org.). Propriedade Intelectual: tensões entre o capital e a sociedade. Pag. 159 São Paulo: Paz e Terra, 2007. 
Com as novas e mais rígidas regras em Propriedade Intelectual, o conhecimento tem se tornado menos acessível e os benefícios que a sociedade obtém desse monopólio não são claros ${ }^{36}$. Os países em desenvolvimento possuem falta de agilidade, capacidade e infraestrutura industrial para competir com os mercados baseados na atividade inovativa. Assim, o alcance do equilíbrio adequado entre os interesses público e privado deve ser a prioridade de qualquer sistema nacional de inovação. É necessário criar uma troca razoável entre o bem-estar e o desenvolvimento tecnológico, devendo os países em desenvolvimento revisar suas próprias necessidades e capacidades, adotando ações e estratégias que reduzam os custos sociais e econômicos gerais ${ }^{37}$. 0 comércio e investimentos devem ser encarados como meios para o alcance do desenvolvimento equitativo e sustentável, e não como metas por si só.

É preciso deixar claro que a propriedade intelectual não é o único fator que contribui para o cenário atual. No entanto, sua contribuição para a desigualdade entre as nações não pode ser desprezada, já que pode se constituir em um entrave para o desenvolvimento de nações "atrasadas" tecnologicamente ${ }^{38}$. Faz-se mister compreender que os direitos de propriedade intelectual são um meio para alcançar o desenvolvimento e outros objetivos específicos, e não um fim em si mesmos. A elaboração de regimes de propriedade intelectual mais equilibrados não é apenas interesse das nações atrasadas tecnologicamente, mas também das desenvolvidas, já que um sistema científico livre e aberto, recompensa a atividade inovativa, ao mesmo tempo em que promove a transferência tecnológica ${ }^{39}$.

O sistema internacional de proteção à propriedade intelectual tal como está, apenas consolida o status quo vigente. Os dados disponibilizados ao longo do presente trabalho corroboram tal entendimento e demonstram que as estratégias adotadas até agora não foram suficientes, ou sequer promoveram alterações na distribuição da produção de conhecimento no plano internacional. 0 atual sistema de proteção à

\footnotetext{
${ }^{36}$ QUIJANO, José Manuel. op cit, pág. 200.

${ }^{37}$ BASSO, Maristela. Gestão do Bilateralismo e Multilateralismo para o alcance de objetivos políticos de PI- os casos da América Latina e Caribe. In: VILLARES, Fábio (org.) Propriedade Intelectual: tensões entre o capital e a sociedade. Pag. 228. São Paulo: Paz e Terra, 2007.

${ }^{38}$ WULK [et al]. Propriedade Intelectual e o desenvolvimento das nações: o Acordo TRIPS e suas

consequências conflituosas no mundo contemporâneo. In: Justiça enquanto Responsabilidade. pag. 185.

39 JAGUARIBE, Roberto; BRANDELLI, Otávio, op. cit, pág. 303-304.
} 
propriedade intelectual constitui-se em um modo de exploração de conhecimento que gera pouquíssimo rendimento social. Apesar de não ser o único meio de se promover o desenvolvimento, a propriedade intelectual é parte importante da estratégia de um país no plano internacional.

Contudo, não se tratam de radicalismos. Defende-se aqui a necessidade de preservar o espaço para a adoção de políticas públicas nacionais, mas em consonância e dentro dos limites estabelecidos pelos compromissos previamente assumidos pelo país. Ao mesmo tempo, entendemos, que apesar do fato de um Estado não poder subverter a norma, ele pode lutar por mudanças no regime, sempre observando o espaço de debate e discussão, de forma a buscar soluções que atendam o interesse de todos.

\section{REFERÊNCIAS}

ALBUQUERQUE, Eduardo da Motta e. Propriedade Intelectual e estratégias para o desenvolvimento. In: VILLARES, Fábio (org.). Propriedade Intelectual: tensões entre o capital e a sociedade. São Paulo: Paz e Terra, 2007

BARBOSA, Denis Borges. Trips e a Experiência Brasileira. In: VARELLA, Marcelo Dias (org.) Propriedade Intelectual e Desenvolvimento. São Paulo: Lex Editora, 2005.

BASSO, Maristela. Gestão do Bilateralismo e Multilateralismo para o alcance de objetivos políticos de PI- os casos da América Latina e Caribe. In: VILLARES, Fábio (org.) Propriedade Intelectual: tensões entre o capital e a sociedade. São Paulo: Paz e Terra, 2007.

CARPES, Mariana Montez. 0 Lugar da Ciência e da Tecnologia nas Relações Internacionais Contemporâneas: antigas e novas relações de poder. Disponível em:< http://www.maxwell.vrac.puc-rio.br/9614/9614_3.PDF>. Acessado em: 17 de outubro de 2015.

CHANG, Ha-Joon. Chutando a escada. A estratégia do desenvolvimento em perspectiva histórica. Tradução: Luiz Antônio Oliveira de Araújo. São Paulo: Editora UNESP, 2004.

CHRISTOVÃO, Daniela. A proteção da propriedade intelectual: uma abordagem internacional. pag.222-223 In: MELO, José Marques de; et al. (org). Sociedade de conhecimento: aportes latino-americanos. São Bernardo do Campo: UMESP: Cátedra Unesco para o Desenvolvimento Regional, 2005. 
CORREA, Carlos M. Analisando tensões entre patentes e interesse público. In: VARELLA, Marcelo Dias. (org.) Propriedade Intelectual e Desenvolvimento. São Paulo: Lex Editora, 2005.

DUPAS, Gilberto. Propriedade Intelectual: tensões entre a lógica do capital e os interesses sociais. In: VILLARES, Fábio (org.) Propriedade Intelectual: tensões entre o capital e a sociedade. São Paulo: Paz e Terra, 2007.

GANDELMAN, Marisa. Poder e conhecimento na economia global. 0 regime internacional da propriedade intelectual da sua formação à regras de comércio atuais. Rio de Janeiro: Civilização Brasileira, 2004.

GUISE, Mônica Steffen. Propriedade Intelectual no Mundo Contemporâneo: Fomento ao desenvolvimento? Pág. 4. Disponível em:

<http://www.egov.ufsc.br/portal/conteudo/propriedade-intelectual-no-mundocontempor\%C3\%A2neo-fomento-ao-desenvolvimento>. Acessado em: 02 de novembro de 2015.

JAGUARIBE, Roberto; BRANDELLI, Otávio. Propriedade Intelectual: espaços para os países em desenvolvimento. In: VILLARES, Fábio (org.) Propriedade Intelectual: tensões entre o capital e a sociedade. São Paulo: Paz e Terra, 2007

KEOHANE, Robert O.; NYE JR, Joseph S. Power and Interdependence in the Information Age. In: ESSAY, September/October 1998.

KRASNER, Stephen D. Causas Estruturais e Consequências dos Regimes Internacionais: Regimes como variáveis intervenientes. In: Rev. Sociol. Polít., Curitiba, v. 20, n. 42, p. 93-110, jun. 2012.

NYE Jr, Joseph S. Cooperação e conflito nas relações internacionais. Uma leitura essencial para entender as questões da política mundial. Tradução: Henrique Amat Rêgo Monteiro. Pág. 247. São Paulo: Editora Gente,2009.

NYE JR. Joseph S. 0 futuro do poder. Tradução: Magda Lopes. Benvirá, 2012

QUIJANO, José Manuel. Inovação e Estratégias para o desenvolvimento. In: VILLARES, Fábio (org.). Propriedade Intelectual: tensões entre o capital e a sociedade. São Paulo: Paz e Terra, 2007.

SARFATI, Gilberto. 0 poder estrutural e o poder brando das empresas Multinacionais. In: Revista de Economia \& Relações Internacionais. volume 7/ número 13/ julho de 2008.

SHERWOOD, Robert M. Propriedade Intelectual e Desenvolvimento Econômico. São Paulo: Edusp, 1992.

STIGLITZ, Joseph E. Economic Foundations of Intellectual Property Rights. In: Duke Law Journal, 2008. 
STRANGE, Susan. States and Markets. London and New York: Pinter, 1988.

S

TRANGE, Susan. STRANGE, Susan. "Cave! Hic Dragones: A Critique of Regime Analysis". In KRASNER, Stephen (ed.). International Regimes. Ithaca, New York: Cornell University Press, 1983.

VARELLA, Marcelo Dias. Políticas Públicas para Propriedade Intelectual no Brasil. In: VARELLA, Marcelo Dias. (org.) Propriedade Intelectual e Desenvolvimento. São Paulo: Lex Editora, 2005.

WORLD INTELLECTUAL PROPERTY ORGANIZATION. World Intellectual Property Indicators. In: Economics \& Statistics Series. 2014.

WULK, [et al]. Propriedade Intelectual e o desenvolvimento das nações: o Acordo TRIPS e suas consequências conflituosas no mundo contemporâneo. In: Justiça enquanto Responsabilidade. 